\title{
Serum amyloid beta-42 as a noninvasive biomarker for the prognosis and histologic features of glioma
}

\section{Kihwan Hwang}

Seoul National University Bundang Hospital

\section{Minhee Noh}

Seoul National University College of Medicine

Jay J. Park

The University of Edinburgh Edinburgh Medical School

\section{Kwang-Sung Ahn}

PDXen Biosystems Inc.

Junhyung Kim

Seoul National University Bundang Hospital

\section{So Young Ji}

Seoul National University Bundang Hospital

\section{Jung Ho Han}

Seoul National University Bundang Hospital

Chae-Yong Kim ( $\nabla$ chaeyong@snu.ac.kr)

Seoul National University College of Medicine https://orcid.org/0000-0001-9773-5553

\section{Research Article}

Keywords: Glioma, Amyloid beta, Serum, Biomarker, Prognosis

Posted Date: August 26th, 2021

DOI: https://doi.org/10.21203/rs.3.rs-836779/v1

License: (c) (i) This work is licensed under a Creative Commons Attribution 4.0 International License.

Read Full License 


\section{Abstract \\ PURPOSE}

Glioma is often refractory. Histopathologic examination is essential to establish an initial diagnosis, and multiple imaging studies are conducted to assess the treatment response. However, these conventional approaches are usually accompanied by high risks and costs during treatment. The purpose of this study was to identify a novel, noninvasive, candidate biomarker for the histological prediction and prognostic assessment of glioma.

\section{METHODS}

Serum was prepared from blood samples collected preoperatively from 65 patients with WHO grade II-IV glioma between October 2004 and December 2017 in a single tertiary-level institution. The concentration of amyloid beta-42 (Aß42) was measured by SMCxPRO (Merck) immunoassay. The clinical characteristics and histologic features of the patients, including the molecular subtype, were reviewed. Progression-free survival was evaluated as the primary outcome.

\section{RESULTS}

The mean age of the patients was $53.7 \pm 12.2$ years. Thirty-seven $(56.9 \%)$ patients were male, and 21 (32.3\%) patients had primary tumors. In Kaplan-Meier survival analysis, the group with higher serum $A \beta 42(>5.7 \mathrm{pg} / \mathrm{ml})$ showed a poorer outcome $(p=0.014)$. In multivariate regression analysis, the serum A 42 concentration showed a significant association with EGFR expression and the Ki- 67 labeling index. A higher serum $A \beta 42$ concentration was associated with wild-type EGFR expression (odds ratio $0.237, p=$ 0.022 ), increased cell proliferation $(\beta=0.339, p=0.007)$ and a poor outcome (hazard ratio $0.339, p=$ 0.046).

\section{CONCLUSION}

The serum A $A 42$ level would be a good, noninvasive, candidate biomarker for the prediction of histological features and prognosis in glioma patients. Further studies with large cohorts might be required for its clinical use.

\section{Introduction}

Glioma is a tumor of glial cell origin responsible for $30 \%$ of central nervous system neoplasms and $80 \%$ of malignant tumors in the brain. [1] High-grade glioma exhibits highly aggressive behavior and a dismal prognosis. Initial diagnosis is made by magnetic resonance imaging (MRI) scans, followed by invasive neurosurgical procedures for histopathological and molecular confirmation. Patients are prone to 
repetitive MRI follow-up with gadolinium-based contrasts to evaluate the response to the treatment, such as radiation therapy or chemotherapy. However, based on current clinical guidelines, the use of MRI to predict prognosis has several problems due to treatment-related changes, like pseudoprogression or pseudoresponse, requiring further examination by positron emission tomography with radioisotopes and sometimes reoperation for biopsy. [2] To the best of our knowledge and experience, these conventional approaches are not only invasive and inconvenient but also highly expensive.

On the other hand, recent studies have suggested novel liquid biopsy-based approaches to improve the limitations of previous methods. Blood-based liquid biopsy has become part of routine clinical care for the detection of therapeutically targetable mutations in many solid tumors outside the brain. [3] Identifying noninvasive biomarkers of glioma is also important. Several new candidates from among circulating DNAs, microRNAs, metabolites and proteins have been reported. [4, 5] However, no circulating biomarker is currently applicable in the clinical setting.

Amyloid beta-42 (AB42) is a peptide consisting of 42 amino acids that is derived from amyloid precursor protein (APP). Previous studies have shown that pan-neural expression of $A \beta 42$ is related to increased glial cell proliferation [6] and reduced epidermal growth factor receptor (EGFR) levels in the brain in in vivo models [7]. In human research, it has been reported that $A \beta$ accumulates in the brain tissue of glioma patients [8] and is detected in CSF and serum [9]. This finding suggests the potential of A 342 as a noninvasive biomarker for glioma.

The purpose of this study was to determine the potential of $A \beta 42$ as a noninvasive biomarker of glioma. To evaluate serum $A \beta 42$ levels, immunoassays were performed with serum sample s from glioma patients.

\section{Methods}

\section{Study population}

Blood samples from glioma patients who agreed and provided informed consent were collected preoperatively between October 2004 and December 2017 at our institution. We also collected demographic and tumor-related clinical data, including age at diagnosis, sex, etiology (primary or recurrent), histopathological grade and tumor subtype based on the World Health Organization (WHO) classification, Ki-67 labeling index, EGFR expression, extent of resection (EOR), and progression-free survival (PFS). This study was approved by the institutional review board of our institution.

\section{Immunoassay for amyloid-beta42}

Samples were used immediately after collection or stored at $-20^{\circ} \mathrm{C}$ before they were subjected to more than two freeze-thaw cycles before use. Reagents from the SMCXPRO (Merck) kit were stored at $4^{\circ} \mathrm{C}$ and thawed at room temperature before the experiment. The antibody used for detection was kept in complete darkness before use. 
The blood sample was centrifuged for 10 minutes at $13000 \mathrm{xg}$ using a microcentrifuge. Only the supernatant was moved to a microcentrifuge tube using a pipette and diluted with a standard diluent reagent at a 1:4 ratio. One hundred microliters of standards and a 1:4 diluted sample were dispensed on each well of the assay plate.

Anti-A $\beta 42$ antibody-coated beads were sufficiently resuspended for at least 20 minutes by using a spin rotator or by manual inversion. The anti-A $\beta 42$ antibody-coated beads $(0.45 \mathrm{ml})$ were then diluted with $11.55 \mathrm{ml}$ of assay buffer. One hundred microliters of the bead solution was dispensed onto each well of the assay plate. The plate was completely sealed and incubated in a microplate shaker at $25^{\circ} \mathrm{C}$ and 500 rpm for 2 hours. After centrifugation with 20X detection antibody for 5 minutes at $14000 \mathrm{xg}, 250 \mu \mathrm{l}$ of the antibody supernatant was mixed with $4750 \mu$ of assay buffer. The diluted antibody was moved to a clean tube using a $0.2 \mu \mathrm{m}$ filter. When incubation of the assay plate was complete, the plate was centrifuged at $1100 \mathrm{xg}$ for one minute, and the seal was opened. The assay plate was placed on a handheld magnet, and the supernatant was removed using a pipette. After the assay plate was displaced from the handheld magnet, $20 \mu \mathrm{l}$ of antibody was added to each well. The plate was covered and placed in a shaker at $25^{\circ} \mathrm{C}$ for 30 minutes.

The plate was placed on the handheld magnet, and the supernatant was removed. The beads were washed four times. At the end of washing, $200 \mu \mathrm{l}$ of $1 \mathrm{X}$ wash buffer was dispensed, after which the plate was displaced from the handheld magnet. After the plate was sealed, it was agitated at $750 \mathrm{rpm}$ for 90 seconds, and the supernatant was carefully removed. Ten microliters of buffer $D$ was dispensed in each well, and the plate was placed on a Sphere mag plate for two minutes. After $10 \mu \mathrm{l}$ of the eluate had been moved from the assay plate to the V-bottom plate for reading, the plate was sealed, agitated at $25^{\circ} \mathrm{C}$ at $1500 \mathrm{rpm}$ for one minute and centrifuged at room temperature at $1100 \mathrm{xg}$ for one minute. The plate was sealed with an aluminum seal and placed in an SMCXPRO for analysis.

\section{Statical analyses}

All data were analyzed using Statistical Package for Social Sciences (SPSS) software version 26.0.0 (IBM, Armonk, NY, USA).

Subjects were divided into two groups by serum $A \beta 42$ concentration. In our study, a healthy control serum A 42 concentration, which is needed to determine the threshold for Kaplan-Meier analysis, was not available. Instead, we performed the Kaplan-Meier analysis several times and compared the $\mathrm{p}$-value from the log-rank tests in Kaplan-Meier analysis to determine the threshold for high or low serum $A \beta 42$ concentration; the threshold was determined to be $5.7 \mathrm{pg} / \mathrm{ml}$, for which the lowest $\mathrm{p}$-value was obtained by log-rank test.

To compare PFS between the high $A \beta 42(>5.7 \mathrm{pg} / \mathrm{ml})$ and low $A \beta 42(\leq 5.7 \mathrm{pg} / \mathrm{ml})$ groups, we used Kaplan-Meier analysis and the log-rank test. Cox proportional hazards regression analysis was used to assess the hazard ratios (HR) for PFS according to the level of serum Aß42. To adjust for the effects of potential confounding factors on PFS, age, sex, tumor subtype, WHO grade and EOR were included as 
covariates in multivariate analysis. The assumption of proportionality for Cox proportional hazards analysis was confirmed by ensuring that the two Kaplan-Meier curves for the high $A \beta 42$ and low $A \beta 42$ groups did not intersect.

To measure associations between histologic features and serum $A \beta 42$ concentration, we calculated standardized coefficients $(\beta)$ and odds ratios (ORs) using linear and logistic regression. A univariate regression model was used to determine variables associated with the Ki-67 labeling index and EGFR expression. A multivariate regression model was used to calculate $\beta$ and the OR after adjusting for age, sex, and other variables that were found significant by univariate analysis $(p<0.05)$.

\section{Results}

\section{Demographics and clinical characteristics of the patients}

A total of 65 patients were included in the final analysis: 43 cases with glioblastoma (WHO grade IV), 11 cases with anaplastic oligodendroglioma (WHO grade III), 5 cases with anaplastic astrocytoma (WHO grade III), 5 cases with oligodendroglioma (WHO grade II), and 1 case with diffuse astrocytoma (WHO grade II) (summarized in Table 1). 
Table 1

Basic characteristics of the subjects studied

\begin{tabular}{|ll|}
\hline Characteristic & Study population $(\mathbf{n}=65)$ \\
\hline Male sex, no. $(\%)$ & $37(56.9)$ \\
\hline Age in years, mean $( \pm$ SD) & $53.7( \pm 12.2)$ \\
\hline Amyloid beta in pg/ml, mean $( \pm$ SD) & $6.26( \pm 4.49)$ \\
\hline Primary tumor, no. (\%) & $21(32.3)$ \\
\hline Diagnosis, no. (\%) & \\
\hline Glioblastoma multiforme & $43(66.2)$ \\
\hline Anaplastic oligodendroglioma & $11(16.9)$ \\
\hline Anaplastic astrocytoma & $5(7.7)$ \\
\hline Oligodendroglioma & $5(7.7)$ \\
\hline Diffuse astrocytoma & $1(1.5)$ \\
\hline WHO grade, no. $(\%)$ & \\
\hline Grade IV & $43(66.2)$ \\
\hline Grade III & $16(24.6)$ \\
\hline Grade II & $6(9.2)$ \\
\hline EGFR mutation, no. (\%) & $46(70.8)$ \\
\hline Ki-67 ${ }^{\dagger}$, mean $( \pm$ SD), \% & $14.71( \pm 11.41)$ \\
\hline Extent of resection, no. (\%) & \\
\hline Gross total resection & $34(52.3)$ \\
\hline Subtotal resection & $16(21.5)$ \\
\hline Partial resection & \\
\hline Biopsy & \\
\hline Data are shown as the median (range) & or number $(\%) .{ }^{\dagger} n=62$ \\
\hline
\end{tabular}

The mean $( \pm S D)$ age of the patients was $53.7 \pm 12.2$ years. The mean serum concentration of $A \beta 42$ was $6.26 \pm 4.49 \mathrm{pg} / \mathrm{ml}$. Twenty-one (32.3\%) patients had primary tumors, and the other $44(67.7 \%)$ patients had recurrent tumors. The mean Ki-67 labeling index was $14.71 \pm 11.41 \%$.

\section{Association between serum A $\beta 42$ concentration and glioma patient prognosis}


Kaplan-Meier analysis demonstrated that patients with high serum $A \beta 42(>5.7 \mathrm{pg} / \mathrm{ml}, \mathrm{n}=30)$ had significantly shorter PFS ( $p=0.014$; Fig. 1). Twenty-four out of 30 patients in the high A 342 group experienced progression, while 18 out of 35 patients in the low A 342 group did. The mean and median PFS of the high $A \beta 42$ group were $29.5 \pm 7.7$ and $13.0 \pm 3.90$ months, respectively, while those of the low $A \beta 42$ group were $67.1 \pm 14.7$ and $38.0 \pm 18.0$ months, respectively.

Univariate and multivariate Cox regression analyses were used to determine independent prognostic factors for PFS. In univariate Cox regression, the level of serum A 342 , tumor subtype, WHO grade and EOR were significant factors for PFS (Table 2). In multivariate Cox regression, a high serum A 42 level (HR 2.021, $p=0.046)$ and grade II glioma (unlike grade IV glioma) (HR 0.241, $p=0.047)$ were independent prognostic factors for PFS after adjusting for age, sex, and other factors that were deemed significant by univariate analysis. 
Table 2

Univariate and multivariate Cox regression analyses of PFS

\begin{tabular}{|c|c|c|c|c|}
\hline \multirow[t]{2}{*}{ Variable } & \multicolumn{2}{|c|}{ Univariate Cox Regression } & \multicolumn{2}{|c|}{ Multivariate Cox Regression } \\
\hline & $\mathrm{HR}(95 \% \mathrm{Cl})$ & p-value & $\mathrm{HR}(95 \% \mathrm{Cl})$ & p-value \\
\hline Sex, female & $0.675(0.365-1.248)$ & 0.210 & $0.730(0.379-1.442)$ & 0.365 \\
\hline Age, $>54$ years & $1.414(0.750-2.665)$ & 0.284 & $0.940(0.460-1.918)$ & 0.864 \\
\hline Amyloid beta & $2.111(1.141-3.908)$ & $0.017 *$ & $2.021(1.011-4.038)$ & $0.046^{*}$ \\
\hline \multicolumn{5}{|l|}{$(>5.7 \mathrm{pg} / \mathrm{ml})$} \\
\hline Primary tumor & $1.209(0.641-2.283)$ & 0.558 & & \\
\hline \multicolumn{5}{|l|}{ Diagnosis } \\
\hline GBM & $5.197(1.197-22.56)$ & $0.028 *$ & $\dagger$ & \\
\hline $\mathrm{AO}$ & $3.349(0.675-16.60)$ & 0.139 & $2.366(0.305-18.37)$ & 0.410 \\
\hline AA & Reference & & Reference & \\
\hline ODG & $2.061(0.376-11.31)$ & 0.405 & $\dagger$ & \\
\hline DA & $3.442(0.303-39.13)$ & 0.319 & $3.169(0.267-37.63)$ & 0.361 \\
\hline \multicolumn{5}{|l|}{ WHO grade } \\
\hline Grade IV & Reference & & Reference & \\
\hline Grade III & $0.432(0.200-0.937)$ & $0.034^{\star}$ & $0.185(0.026-1.340)$ & 0.095 \\
\hline Grade II & $0.445(0.166-1.189)$ & 0.106 & $0.241(0.059-0.984)$ & $0.047^{*}$ \\
\hline EGFR mutation & $0.925(0.485-1.763)$ & 0.813 & & \\
\hline Ki-67, > 15\% & $1.094(0.517-2.316)$ & 0.814 & & \\
\hline \multicolumn{5}{|l|}{ EOR, no. (\%) } \\
\hline GTR & $3.750(1.484-9.477)$ & $0.005^{\star}$ & $1.881(0.579-6.106)$ & 0.293 \\
\hline STR & Reference & & Reference & \\
\hline PR & $3.522(1.295-9.578)$ & $0.014^{\star}$ & $2.614(0.779-8.772)$ & 0.120 \\
\hline$B x$ & $0.000(0.000)$ & 0.980 & $0.000(0.000)$ & 0.979 \\
\hline
\end{tabular}

${ }^{*} \mathrm{p}$-value $<0.05 ;{ }^{\dagger}$ The degree of freedom is zero.

AA, anaplastic astrocytoma; $\mathrm{AO}$, anaplastic oligodendroglioma; Bx, biopsy; DA, diffuse astrocytoma; EOR, extent of resection; GBM, glioblastoma multiforme; GTR, gross total resection; ODG, oligodendroglioma; PR, partial resection; STR, subtotal resection 
Unlike PFS, which was strongly associated with serum A 342 levels, the overall survival (OS) of glioma patients showed no association with serum $A \beta 42$ levels in Kaplan-Meier analysis $(p=0.409)$. Over the observation period, six out of 30 patients in the high $A \beta 42$ group expired, and 4 out of 35 patients in the low $A \beta 42$ group did.

\section{Association between serum A 342 concentration and histologic features of the glioma patients}

Linear and logistic regression analyses were performed to determine whether the $A \beta 42$ concentration in the serum of glioma patients was a significant predictor of the Ki-67 labeling index and EGFR expression.

In univariate linear regression analysis for the Ki-67 labeling index, age was a significant factor (Table 3). However, after adjusting for sex and age, the serum $A \beta 42$ level was a significant factor for the Ki-67 labeling index $(\beta=0.339, p=0.007)$. The Ki-67 labeling index, which is related to cell proliferation, was higher in the high $A \beta 42$ group than in the low $A \beta 42$ group. 
Table 3

Univariate and multivariate linear regression analyses of $\mathrm{Ki}-67$ (\%)

\begin{tabular}{|c|c|c|c|c|c|}
\hline \multirow[t]{2}{*}{ Variable } & \multicolumn{2}{|c|}{ Univariate Regression } & \multicolumn{3}{|c|}{ Multivariate Regression } \\
\hline & $\beta \pm S E$ & p-value & $\beta \pm S E$ & p-value & $R^{2}\left(\operatorname{adj} . R^{2}\right)$ \\
\hline Sex, female & $-0.136 \pm 2.953$ & 0.293 & $-0.170 \pm 2.711$ & 0.153 & \multirow[t]{4}{*}{$0.208(0.168)$} \\
\hline Age (years) & $0.288 \pm 0.116$ & $0.023^{*}$ & $0.373 \pm 0.114$ & $0.003^{*}$ & \\
\hline Amyloid beta & $0.230 \pm 0.315$ & 0.072 & $0.339 \pm 0.304$ & $0.007 *$ & \\
\hline \multicolumn{5}{|l|}{$(>5.7 \mathrm{pg} / \mathrm{ml})$} & \\
\hline Primary tumor & $-0.075 \pm 3.212$ & 0.579 & & & \\
\hline \multicolumn{6}{|l|}{ Diagnosis } \\
\hline AA & $-0.020 \pm 0.020$ & 0.913 & & & \\
\hline DA & $-0.070 \pm 12.84$ & 0.628 & & & \\
\hline GBM & $0.211 \pm 6.015$ & 0.405 & & & \\
\hline $\mathrm{AO}$ & $0.246 \pm 6.704$ & 0.281 & & & \\
\hline ODG & Reference & & & & \\
\hline \multicolumn{6}{|l|}{ WHO grade } \\
\hline Grade II & $-0.151 \pm 5.438$ & 0.252 & & & \\
\hline Grade III & $-0.011 \pm 3.384$ & 0.931 & & & \\
\hline Grade IV & Reference & & & & \\
\hline EGFR mutation & $-0.067 \pm 3.334$ & 0.604 & & & \\
\hline \multicolumn{6}{|c|}{${ }^{*} \mathrm{p}$-value $<0.05 ; \mathrm{SE}$, standard error } \\
\hline
\end{tabular}

In univariate logistic regression analysis for EGFR mutation, the serum A 42 level and etiology were significant factors (Table 4). After adjusting for age, sex and the etiology of the tumor, the serum A 342 level was still a significant factor for EGFR mutation (OR 0.237, $p=0.022)$. This means that wild-type EGFR was expressed at greater levels when the serum $A \beta 42$ level was high. 
Table 4

Univariate and multivariate logistic regression analyses of EGFR mutation

\begin{tabular}{|c|c|c|c|c|}
\hline \multirow[t]{2}{*}{ Variable } & \multicolumn{2}{|l|}{ Univariate Regression } & \multicolumn{2}{|c|}{ Multivariate Regression } \\
\hline & OR & P-value & $\mathrm{OR}(95 \% \mathrm{Cl})$ & P-value \\
\hline Sex, female & $0.782(0.267-2.291)$ & 0.654 & $0.653(0.197-2.163)$ & 0.495 \\
\hline Age, $>54$ years & $2.364(0.766-7.296)$ & 0.135 & $1.953(0.566-6.743)$ & 0.290 \\
\hline $\begin{array}{l}\text { Amyloid beta } \\
(>5.7 \mathrm{pg} / \mathrm{ml})\end{array}$ & $0.271(0.087-0.844)$ & $0.024^{\star}$ & $0.237(0.069-0.812)$ & $0.022^{\star}$ \\
\hline Primary tumor & $0.283(0.092-0.873)$ & $0.028^{*}$ & $0.272(0.079-0.943)$ & $0.040^{*}$ \\
\hline \multicolumn{5}{|l|}{ Diagnosis } \\
\hline AA & $6.000(0.354-101.6)$ & 0.214 & & \\
\hline DA & $2423212264(0.000)$ & 1.000 & & \\
\hline GBM & $4.95(0.723-33.90)$ & 0.103 & & \\
\hline AO & $6.000(0.210-15.41)$ & 0.214 & & \\
\hline ODG & Reference & & & \\
\hline \multicolumn{5}{|l|}{ WHO grade } \\
\hline Grade II & $0.303(0.053-1.743)$ & 0.181 & & \\
\hline Grade III & $0.505(0.147-1.736)$ & 0.278 & & \\
\hline Grade IV & Reference & & & \\
\hline Ki-67, >15\% & $1.059(0.286-3.920)$ & 0.932 & & \\
\hline \multicolumn{5}{|c|}{${ }^{*}$ P-value $<0.05 ; \mathrm{SE}$, standard error } \\
\hline $\begin{array}{l}\text { AA, anaplastic a } \\
\text { glioblastoma m }\end{array}$ & $\begin{array}{l}\text { ytoma; AO, anaplasti } \\
\text { rme; ODG, oligodendr }\end{array}$ & $\begin{array}{l}\text { dendro } \\
\text { na; OR, }\end{array}$ & $\begin{array}{l}\text { A, diffuse astrocytom } \\
\text { O }\end{array}$ & \\
\hline
\end{tabular}

\section{Discussion}

In this study, serum Aß42 levels were investigated as a candidate noninvasive biomarker of glioma. The results demonstrated that a high concentration of serum AB42 was associated with wild-type EGFR expression, a high Ki-67 index and poor PFS.

Glial cell proliferation and EGFR expression are important factors for the evaluation of glioma. The level of proliferative activity, represented by the Ki- 67 labeling index, is an ancillary tool for the grading of gliomas. $[10,11]$ The Ki-67 labeling index, the fraction of Ki-67-positive tumor cells, is often correlated 
with the clinical course of disease. [12] Ki-67 expression might be a predictive factor for poor prognosis in glioma. $[12,13]$ EGFR is a transmembrane tyrosine kinase, and EGFR signaling leads to DNA synthesis and cellular proliferation. [14] EGFR is modified in several ways in glioma through overexpression, amplification, deletion, and other effects. Alterations in EGFR promote proliferation, survival, angiogenesis and invasion. [15] Although the clinical relevance of alterations in EGFR in glioma remains controversial, our study shows a possible association between the expression of EGFR and prognosis of glioma patients. $[15,16]$ Our research is consistent with previous studies showing that neural expression of $A \beta 42$ reduces EGFR expression in the brain and induces glial cell proliferation. $[6,7]$

Pan-neural expression of A 442 reduced total EGFR expression in the brains of 25-day-old Drosophila and 8-month-old mice, although the mechanism by which EGFR expression was suppressed by A $\beta 42$ is still unclear. [7] However, a previous study showed that the intracellular domain of APP is important for the regulation of brain EGFR expression. Overexpression of the intracellular domain of APP reduced EGFR levels in the brains of APP-knockout mice, but overexpression of $A \beta$ did not. [17] How, then, can we explain our finding that $A \beta 42$ is associated with suppression of EGFR expression? Although $A \beta 42$ alone cannot regulate EGFR expression, A 342 might affect EGFR expression by inducing APP production. [18]

Additionally, pan-neural expression of A 342 in Drosophila increased the number of glial cells in the larval brain. [6] In the same study, researchers showed the consumption of PD98059, a specific ERK inhibitor, did not affect glial cell proliferation throughout the neurons of A 42 -expressing Drosophila. This result suggests that the increased glial cell proliferation induced by $A \beta 42$ was not associated with the ERK/EGFR signaling pathway. This can explain our finding that a high serum A 342 concentration was associated with increased glial cell proliferation and reduced EGFR expression. Mechanisms other than ERK/EGFR signaling may be involved in the induction of glial cell proliferation by $A \beta 42$.

Although we found that serum $A \beta 42$ levels were associated with the histologic features and prognosis of glioma, our current study is limited for several reasons. First, it is a retrospective study. Based on our results, we could not assess the effect of tumor resection on serum A 42 levels. Thus, we could not determine whether serum A $\beta 42$ levels were affected by the tumor itself. Second, all patients were Korean; hence, the results cannot be applied generally to other ethnic groups. Third, there is a possibility of selection bias because our sample size was small, and the patients were enrolled from a single institution. Finally, we used the 2007 WHO classification of CNS tumors, and patients had various tumor subtypes from grade II to IV. The heterogeneity of tumor subtypes and use of an old classification system are limitations of this study. Prospective studies with larger cohorts from multiple centers and the use of an updated WHO classification of CNS tumors are future aims to reinforce the results of our study.

In summary, our results suggest that serum $A \beta 42$ levels are a noninvasive biomarker for the histologic features and prognosis of glioma. Further prospective studies with larger cohorts from multiple institutions might be required for the clinical use of $A \beta 42$ as a biomarker for glioma.

\section{Abbreviations}


Amyloid beta-42, Aß42

Amyloid precursor protein, APP

Epidermal growth factor receptor, EGFR

Extent of resection, EOR

Hazard ratio, HR

Magnetic resonance imaging, MRI

World Health Organization, WHO

Odds ratio, $\mathrm{OR}$

Progression-free survival, PFS

\section{Declarations}

\section{Author contributions}

Conception and design: K.-S.A. and C.-Y.K.

Acquisition of data: All authors.

Analysis and interpretation of data: K.H. and M.N.

Drafting and revision of the manuscript: All authors.

Final approval: All authors.

\section{Data availability}

Raw data that supports the findings of this study are available from the corresponding author, upon reasonable request.

\section{Funding}

No funding was received to assist with the preparation of this manuscript.

\section{Conflict of interest}

All the authors declare that they have no conflict of interest.

\section{Ethical Approval}


Approved by institutional review board.

\section{References}

1. Goodenberger ML, Jenkins RB (2012) Genetics of adult glioma. Cancer genetics 205:613-621. doi:10.1016/j.cancergen.2012.10.009

2. Delgado-López PD, Riñones-Mena E, Corrales-García EM (2018) Treatment-related changes in glioblastoma: a review on the controversies in response assessment criteria and the concepts of true progression, pseudoprogression, pseudoresponse and radionecrosis. Clinical translational oncology: official publication of the Federation of Spanish Oncology Societies of the National Cancer Institute of Mexico 20:939-953. doi:10.1007/s12094-017-1816-x

3. Bettegowda C, Sausen M, Leary RJ, Kinde I, Wang Y, Agrawal N, Bartlett BR, Wang H, Luber B, Alani RM, Antonarakis ES, Azad NS, Bardelli A, Brem H, Cameron JL, Lee CC, Fecher LA, Gallia GL, Gibbs P, Le D, Giuntoli RL, Goggins M, Hogarty MD, Holdhoff M, Hong SM, Jiao Y, Juhl HH, Kim JJ, Siravegna G, Laheru DA, Lauricella C, Lim M, Lipson EJ, Marie SK, Netto GJ, Oliner KS, Olivi A, Olsson L, Riggins GJ, Sartore-Bianchi A, Schmidt K, Shih IM, Oba-Shinjo SM, Siena S, Theodorescu D, Tie J, Harkins TT, Veronese S, Wang TL, Weingart JD, Wolfgang CL, Wood LD, Xing D, Hruban RH, Wu J, Allen PJ, Schmidt CM, Choti MA, Velculescu VE, Kinzler KW, Vogelstein B, Papadopoulos N, Diaz LA Jr (2014) Detection of circulating tumor DNA in early- and late-stage human malignancies. Science translational medicine 6:

224ra224

doi:10.1126/scitranslmed.3007094

4. Müller Bark J, Kulasinghe A, Chua B, Day BW, Punyadeera C (2020) Circulating biomarkers in patients with glioblastoma. British journal of cancer 122:295-305. doi:10.1038/s41416-019-0603-6

5. Yekula A, Muralidharan K, Rosh ZS, Youngkin AE, Kang KM, Balaj L, Carter BS (2020) Liquid Biopsy Strategies to Distinguish Progression from Pseudoprogression and Radiation Necrosis in Glioblastomas. Advanced biosystems 4:e2000029. doi:10.1002/adbi.202000029

6. Park SH, Lee S, Hong YK, Hwang S, Lee JH, Bang SM, Kim YK, Koo BS, Lee IS, Cho KS (2013) Suppressive effects of SuHeXiang Wan on amyloid- $\beta 42$-induced extracellular signal-regulated kinase hyperactivation and glial cell proliferation in a transgenic Drosophila model of Alzheimer's disease. Biol Pharm Bull 36:390-398. doi:10.1248/bpb.b12-00792

7. Wang L, Liang B, Zhong Y (2013) Reduced EGFR level potentially mediates the A $\beta 42$-induced neuronal loss in transgenic fruit fly and mouse. Protein cell 4:647-649. doi:10.1007/s13238-0133043-8

8. Zayas-Santiago A, Díaz-García A, Nuñez-Rodríguez R, Inyushin M (2020) Accumulation of amyloid beta in human glioblastomas. Clin Exp Immunol 202:325-334. doi:10.1111/cei.13493

9. Gagni P, Sola L, Cretich M, Chiari M (2013) Development of a high-sensitivity immunoassay for amyloid-beta 1-42 using a silicon microarray platform. Biosens Bioelectron 47:490-495. doi:10.1016/j.bios.2013.03.077 
10. Louis DN, Perry A, Reifenberger G, von Deimling A, Figarella-Branger D, Cavenee WK, Ohgaki H, Wiestler OD, Kleihues P, Ellison DW (2016) The 2016 World Health Organization Classification of Tumors of the Central Nervous System: a summary. Acta Neuropathol 131:803-820. doi:10.1007/s00401-016-1545-1

11. Torp SH (2002) Diagnostic and prognostic role of Ki67 immunostaining in human astrocytomas using four different antibodies. Clinical neuropathology 21:252-257

12. Scholzen T, Gerdes J (2000) The Ki-67 protein: from the known and the unknown. Journal of cellular physiology 182: 311-322 doi:10.1002/(sici)1097-4652(200003)182:3<311::Aid-jcp1>3.0.Co;2-9

13. Chen WJ, He DS, Tang RX, Ren FH, Chen G (2015) Ki-67 is a valuable prognostic factor in gliomas: evidence from a systematic review and meta-analysis. Asian Pacific journal of cancer prevention: APJCP 16:411-420. doi:10.7314/apjcp.2015.16.2.411

14. Oda K, Matsuoka Y, Funahashi A, Kitano H (2005) A comprehensive pathway map of epidermal growth factor receptor signaling. Molecular systems biology 1: 2005.0010 doi:10.1038/msb4100014

15. Saadeh FS, Mahfouz R, Assi HI (2018) EGFR as a clinical marker in glioblastomas and other gliomas. Int J Biol Mark 33:22-32. doi:10.5301/ijbm.5000301

16. Xu B, Huo Z, Huang H, Ji W, Bian Z, Jiao J, Sun J, Shao J (2021) The expression and prognostic value of the epidermal growth factor receptor family in glioma. BMC Cancer 21:451. doi:10.1186/s12885-021-08150-7

17. Zhang YW, Wang R, Liu Q, Zhang H, Liao FF, Xu H (2007) Presenilin/gamma-secretase-dependent processing of beta-amyloid precursor protein regulates EGF receptor expression. Proc Natl Acad Sci USA 104:10613-10618. doi:10.1073/pnas.0703903104

18. Tabaton M, Zhu X, Perry G, Smith MA, Giliberto L (2010) Signaling effect of amyloid-beta(42) on the processing of AbetaPP. Exp Neurol 221:18-25. doi:10.1016/j.expneurol.2009.09.002

\section{Figures}




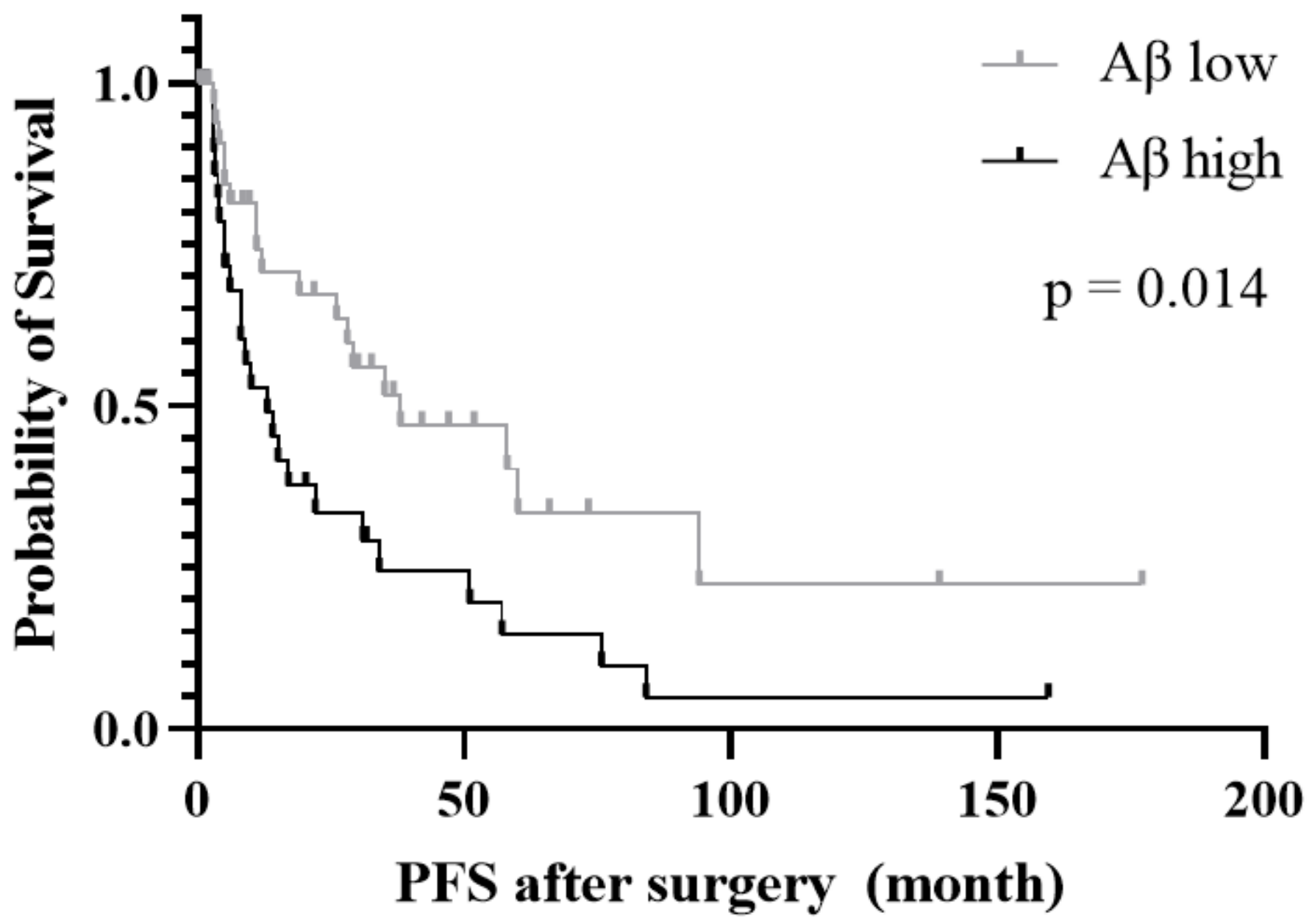

Figure 1

Kaplan-Meier curves for glioma patient PFS based on serum A 442 level. Kaplan-Meier curves display the PFS of patients with high Aß42 levels $(n=30)$ and those with low $A \beta 42$ levels $(n=35)$. 